\title{
Water Allocation Strategies: Experimental Evidence from Uzbekistan
}

\author{
Andrey Zaikin, Ana Espínola-Arredondo, Alejandro Prera \\ School of Economic Sciences, Washington State University, Pullman, USA \\ Email: azaikin@wsu.edu, anaespinola@wsu.edu, alejandro.prera@wsu.edu
}

How to cite this paper: Zaikin, A., Espínola-Arredondo, A. and Prera, A. (2018) Water Allocation Strategies: Experimental Evidence from Uzbekistan. Journal of Water Resource and Protection, 10, 20-40. https://doi.org/10.4236/jwarp.2018.101002

Received: December 14, 2017

Accepted: January 22, 2018

Published: January 25, 2018

Copyright (๑) 2018 by authors and Scientific Research Publishing Inc. This work is licensed under the Creative Commons Attribution International License (CC BY 4.0).

http://creativecommons.org/licenses/by/4.0/

\section{cc) (i) Open Access}

\begin{abstract}
Irrigation water is a scarce common-pool resource in Uzbekistan, which leads to an increasing competition over its allocation among farmers. We examine how the management of this resource affects individual strategic behavior and how its availability (vis-a-vis scarcity vs. non-scarcity) impacts cooperation. We conduct a field experiment in Uzbekistan where two policies are analyzed: penalty and bonus. Our findings suggest that both penalty and bonus mechanisms are effective in reducing individual water appropriation compared to the case in which these policies are absent. However, in terms of reducing overall water appropriation, the bonus mechanism is the most effective in preserving the resource stock. Therefore, policymakers should have a degree of flexibility regarding the selection of a mechanism to reduce water consumption. We also find that subjects exhibit different appropriation behaviors depending on their location within the irrigation system, with upstream users being more sensitive to water reduction than downstream users.
\end{abstract}

\section{Keywords}

Common-Pool Resources, Field Experiment, Non-Cooperative Games, Uzbekistan, Water

\section{Introduction}

Uzbekistan is a double-landlocked, arid country that depends heavily on irrigated agriculture. The agricultural sector is dominated by state-funded programs designed to ensure cotton and wheat production, since 85 percent of cultivated acreage is devoted to these two crops [1]. Because of the dry climate, almost all the cultivated land is irrigated. Unfortunately, water shortages that can significantly reduce production are becoming more frequent and severe, and threaten to undermine the agricultural sector, which accounts for 19 percent of the coun- 
try's GDP in 2014 (World Bank, 2016) ${ }^{1}$. Furthermore, the obsolete water management system and policies, created for collective farms during the Soviet time, concentrate on output instead of water use efficiency and environmental sustainability. An analysis of individual strategic behavior in allocating water resources is, hence, necessary in this particularly arid region. This study seeks to identify potential solutions for the wasteful water allocation among farmers, as well as to prevent the devastating environmental and economic damages that could result from a future depletion of the country's water resource.

We investigate how water use in the area would be affected by different policy mechanisms through a field experiment that strives to imitate a real-life situation of irrigation water appropriation decision with farmers from Djizzak region, Uzbekistan, who regularly face water shortages. We develop three scenarios to characterize different policy approaches: baseline (or benchmark case), penalty, and bonus scenarios. The baseline case represents the status quo in which participants do not face any regulatory policy in water management. The penalty scenario, however, punishes those subjects who overuse the resource, while the bonus scenario, by contrast, rewards subjects who conserve water. The goal is to evaluate, through a field experiment, the effectiveness of these two alternative mechanisms in eliciting cooperation in a common-pool resource dilemma with random variation in resource stock. Resource stock variation is based on the precipitation level that is randomly determined in the experiment by a lottery mechanism. This allows us to analyze whether farmers behave differently when the resource stock is scarce or abundant.

With the data gathered from the field experiment, we test the policy scenarios on a variety of environmental and institutional settings. We start by examining whether farmers' actual use of the resource approaches to our theoretical predictions and, in addition, whether the penalty and bonus mechanisms lead to more efficient appropriations than the baseline scenario. To the best of our knowledge, this is the first field experiment in Uzbekistan analyzing actual farmers' strategic behavior regarding water management.

We find that farmers tend to over-consume the total available resource stock, a behavior that is emphasized when the stock becomes scarcer due to low precipitation. This overuse can be explained by the previous Soviet-era commandand-control administrative system, which focused only on agricultural output without considering water use efficiency and water constraints. The experimental results also show that the penalty and bonus mechanisms reduce individual water appropriation compared to the benchmark case where policy intervention is absent. Furthermore, the bonus mechanism is the most effective policy in preserving the resource stock, especially when the stock is scarce. Specifically, the bonus mechanism is more effective since: 1) the individual and the group appropriation are, on average, lower (evidence of bonus effectiveness); and 2) the compensation from potentially lost crops provides incentives to farmers to pro-

${ }^{1}$ World Development Indicators at http://data.worldbank.org/indicator/NV.AGR.TOTL.ZS. 
tect the resource (reason for bonus effectiveness). Finally, our results suggest that farmers' appropriation choices are quite different depending on their actual location within the irrigation system. We find that downstream farmers chose a higher level of appropriation under the baseline scenario and partially reduce their appropriation under both mechanisms. This result can be understood by the fact that downstream farmers face more uncertainty about receiving enough water than upstream farmers. That is, their location emphasizes the tragedy of a dry season, thus, making them to overuse the resource.

Related Literature. There are a limited number of studies that use field experiments to analyze strategic behavior of irrigation water management in developing countries [2] [3]. To our knowledge, no other studies have conducted an experiment to evaluate the strategic behavior of farmers in relation to irrigation water appropriation in Uzbekistan. [4] and [5] use a cooperative analysis, whereby agents collectively decide the water use for the group, and focus on how to promote cooperation. Their results indicate that water trade significantly increases cooperation and welfare. Our paper complements this research, by studying farmers' strategic behavior in their individual choice of irrigation water in Uzbekistan. Unlike these papers, we analyze the effectiveness of commonly recommended policies, such as penalties and bonuses, in protecting the CPR. A laboratory experiment that investigates regional negotiation between Kyrgyzstan, Uzbekistan and Kazakhstan over water (from the shared Syr Darya river) by imitating the strategic environment in which these countries bargain is developed by [6]. The experimental results indicate that cooperation rarely arises and that it becomes especially difficult in low-water years.

An experiment conducted at Indiana University analyzes a CPR with limited access [7]. The experimental results indicate that the pattern of individuals' decisions does not converge to the Nash equilibrium after several rounds of interactions. Our paper extends this result to settings in which the stock's abundance is randomly determined in every period. [8] [9], and [10] also analyze a CPR under uncertainty about the size of the initial stock. [11] implements an experiment analyzing a CPR game in which subjects do not have precise information about the payoff structure. Similar to our paper, [12] analyze a CPR assuming uncertainty about the resource size and considering bonus and penalty mechanisms. Their experimental results, however, show that both treatments significantly reduce the use of the resource and increase the rate of provision. But penalty treatment is more effective in reducing individual appropriation. [13] develop an experiment to study the nature of enforcement rules (inspection and sanctions) in a CPR where individuals monitor each other's actions. ${ }^{2}$ The monitoring mechanism considerably promotes an efficient use of the resource, especially when sanctions are larger. Finally, similar to [6], our study investigates cooperative behavior assuming complete information of the resource size. However, we examine farmers individual use of water (rather than countries' negotiations), and

${ }^{2}$ The experiment structure is based on Italian Alps' institutions that have been used for centuries. 
allow for different stocks. In addition, our paper explicitly examines tools that help ameliorate free riding behavior. The finding of this study shed light on the potential for introducing penalty and bonus mechanisms while designing a policy for Water User Associations (WUA) by governmental agencies and other policymakers not only in Uzbekistan but also other Central Asian countries.

The structure of the paper is as follows: Section 2 discusses the model and provides a theoretical analysis for the three different scenarios, Section 3 describes the experiment, while Section 4 discusses the results. Finally, Section 5 concludes.

\section{Theoretical Model}

\subsection{Baseline Scenario}

We begin with a single-stage, non-cooperative, $n$-person CPR game in which a group of $N$ players can appropriate a common-pool resource whose exact size is exogenously given. Every player $i(i \in N)$ chooses a nonnegative integer amount $x_{i}$, where $x_{i} \in[0,1, \cdots, 10] .{ }^{3}$ The payoff function of player $i$ is given by:

$$
U\left(x_{i}\right)=\left(\frac{x_{i}}{X}\right)\left[a X-b X^{2}\right]+c\left(W_{r}+R W_{P}-X\right)
$$

where $X=\sum_{i=1}^{N} x_{i}$ denotes the total level of appropriation of the resource. The first term of the payoff function represents the benefits accruing to player $i$ which depend on his individual appropriation, $x_{i}$, and the other players' appropriation levels. Similar to [7] [11] [13] [14] and [15], we use a quadratic production function to calculate the individual payoff as a proportion of the total group appropriation level of the resource. This functional form implies diminishing returns to production, describing, for instance, a reduction in farmers' yields when the group appropriation of water is very high. We do not explicitly assume costs for the use and extraction of water, since these costs are captured by the parameter $b$. In addition, $a$ and $b$ are positive parameters $(a, b>0)$ where $b \in(0,1)$ and $a>b$.

The second part of the payoff function represents player is benefits/disutility from the stock availability and the aggregate appropriation level. ${ }^{4}$ We assume that the total stock consists of permanent and additional stocks. The permanent stock represents the amount of water in the river, $W_{r}$. The additional stock, $R W_{P}$, represents water accumulated from precipitation. $R$ is the level of precipitation and it is a random variable, where $R \in[0,1], W_{P}$ is the maximum amount of precipitation water (e.g., 50 units), and $c$ is a positive constant representing the payment per a unit of conserving/overusing irrigation water.

\footnotetext{
${ }^{3}$ The individual action space is limited to the interval between 0 and 10 to avoid large negative payoffs. In addition, players choose only integer numbers in order to avoid a complexity in reporting their outcome points.

${ }^{4}$ It captures a basic feature of many CPR dilemmas in which overuse of the resource bring 1) negative externalities and 2) positive benefits in case of conservation of the resource. This rule can be applied to a variety of ecological system (e.g., rivers, fisheries, and lakes).
} 
Hence, the second element of the payoff function represents player is disutility if the group overuses the total available stock, $W_{r}+R W_{P} \leq X$, or player is benefits if the group underuses the total available stock, $W_{r}+R W_{P}>X$.

Summarizing, the individual payoff depends on the individual appropriation level, $x_{i}$, group appropriation of the CPR, $X$, and the total available stock. Player $i$ s best response function is a linear function of all other players appropriation, $X_{-p}$

$$
x_{i}\left(X_{-i}\right)=\frac{a-c}{2 b}-\frac{1}{2} X_{-i}
$$

where $X_{-i}=\sum_{j \neq i}^{N} x_{j}$. In addition, $x_{i}\left(X_{-i}\right)$ decreases in the total use of the resource by other players and does not depend on the resource stock. In our experiment we use the same parameters values as in Walker et al. (1990), $(a=23, b$ $=0.25$, and $c=5$ ), hence function (2) can be expressed as:

$$
x_{i}=36-\frac{1}{2} X_{-i}
$$

The Nash equilibrium (NE) is obtained by solving (2) for all players $i \in N$, hence by symmetry $x_{i}^{N E}=\frac{a-c}{(N+1) b}$. It is easy to show that the equilibrium ap propriation level, $x_{i}^{N E}$, decreases in the group size, $N$. Substituting the parameter values used in the experiment and considering $N=10$ (number of participants per group) yields $x_{i}^{N E} \approx 7$. The Socially optimal (SO) appropriation level that maximizes group payoffs, is $x_{i}^{S O}=\frac{a-c}{2 N b}$, or $x_{i}^{S O} \approx 4$. This scenario and its theoretical predictions establish a benchmark to experimentally investigate the effects of penalty and bonus mechanisms on a CPR environment.

\subsection{Penalty Scenario}

The mechanism is designed to reduce the water appropriation by imposing a penalty on the subject with the highest appropriation level. Our goal is to test whether this mechanism induces socially optimal behavior and we derive the conclusions through our field experiment with farmers. The penalty model generates a reduction in the payoff of the player who selects the highest appropriation level of resource, i.e., $\bar{x}$. In particular, his payoff function includes a third term that represents the penalty, that is,

$$
U_{i}^{P}(\bar{x})=\frac{\bar{x}}{X}\left[a X-b X^{2}\right]+c\left(W_{r}+R W_{p}-X\right)-\left[U_{i}(\bar{x})-U_{j}(\underline{x})\right],
$$

where $i \neq j, U_{i}(\bar{x})$ is player $i$ s payoff in the baseline scenario when he chooses the highest appropriation level $\bar{x}$, while $U_{j}(\underline{x})$ is player $j$ s utility from selecting the lowest level of appropriation, $\underline{x}$, among all the other players. If player $i$ chooses the highest appropriation level, a penalty is assessed and is represented by $\left[U_{i}(\bar{x})-U_{j}(\underline{x})\right]$. The penalty mechanism makes player $i$ compensate player $j$ (who behaves cooperatively) for the loss in payoff due to player 
is over-appropriation. Player is utility coincides with player $j$ s payoff from selecting the lowest appropriation level.

$$
U_{i}^{P}(\bar{x})=\underbrace{\frac{\bar{x}}{X}\left[a X-b X^{2}\right]+c\left(W_{r}+R W_{p}-X\right)}_{U_{i}(\bar{x})}-\left[U_{i}(\bar{x})-U_{j}(\underline{x})\right]=U_{j}(\underline{x}) .
$$

Hence, there are an infinite number of possible combinations for the NE solution.

\subsection{Bonus Scenario}

This mechanism is designed to reduce the water appropriation by providing a reward to the subject with the lowest appropriation level. We next present the bonus mechanism that also induces players to select lower appropriation levels and promotes greater conservation of the resource ${ }^{5}$. Several studies provide evidence that a bonus mechanism generates economic incentives for reducing appropriation levels eliciting cooperation. ${ }^{6}$ However, choosing a lower level of appropriation reduces a player's farm output relative to other players. Nonetheless, a lower appropriation might be compensated with a bonus if it is the lowest among all appropriations chosen by the subjects.

Specifically, the payoff function of the player selecting the lowest appropriation level $(\underline{x})$ now contains a bonus component:

$$
U_{i}^{B}(\underline{x})=\frac{\underline{x}}{X}\left[a X-b X^{2}\right]+c\left(W_{r}+R W_{p}-X\right)+\left[U_{j}(\bar{x})-U_{i}(\underline{x})\right]
$$

where $i \neq j, U_{j}(\bar{x})$ denotes player $j$ s utility in the baseline scenario when the highest appropriation is chosen, whereas $U_{i}(\underline{x})$ is player $i$ s utility when the lowest appropriation is selected. Hence, the utility can be represented by the payoff that player $j$ obtains from selecting the highest appropriation level $\bar{x}$ :

$$
U_{i}^{B}(\underline{x})=\underbrace{\frac{\underline{x}}{X}\left[a X-b X^{2}\right]+c\left(W_{r}+R W_{p}-X\right)}_{U_{i}(\underline{x})}+\left[U_{j}(\bar{x})-U_{i}(\underline{x})\right]=U_{j}(\bar{x})(7)
$$

Similar to the penalty scenario, there are an infinite number of possible solutions for the NE solution. The next sections discuss the specifics of our experiment and the results.

\section{Experiment}

\subsection{Area of Study}

Our experiment was conducted among the farmers in the town of Dashtobod, Djizzak province, Uzbekistan. This province borders with Kazakhstan in the north, the Uzbek province of Tajikistan in the south, the Syrdarya province in the east, the Samarkand province in the southwest, and the Navoi province in the west. The climate typically experiences dry and hot summers and mild win${ }^{5} \mathrm{We}$ do not focus on how the bonus can be funded. It may be provided by some government agency or financed through taxes.

${ }^{6}$ See [12] [16] [17] and [18]. 
ters. The mean annual precipitation for the province is relatively scarce (approximately $230 \mathrm{~mm}$ ), occurring generally in the winter-spring seasons. ${ }^{7}$ This area is dominated by a flat extensive plain that can be used for agricultural production only through irrigation.

Most famers, however, exhibit water-deficit problems due to a poor management and the declining technical conditions of the irrigation infrastructure. Figure 1 shows the irrigation system map for this region. The water is diverted from the Syr Darya river that is then lifted through several pump-stations in the northern Syrdarya province, then distributed through the Southern Mirzachul Canal (SMC), and finally through three canals: Djizzak Machinery (DM) Canal $\mathrm{N}^{\circ} 1, \mathrm{~N}^{\circ} 2$ and $\mathrm{N}^{\circ} 3$ to local the Water Utility Authority (WUA). Farmers are not charged for the amount of irrigation water used, but instead pay a fixed annual fee for delivering water and maintaining the irrigation canal based on hectares of land irrigated. Moreover, water volume authorized to deliver to their farms depends on the types of crops they cultivate.

All subjects in the experiment are members of the Kanal Suv Yuli WUA. This association consists of 42 farms ranging between 10 and 179 ha. The total area of the WUA is 2539 ha. The land is mainly used for wheat (60\%) and cotton (30\%), leaving the remaining 10 percent to crops like onion, corn, and melon. ${ }^{8}$ Moreover, the total length of the canals is 2200 meters and the water used for irrigation in these farms is lifted by a pump-station and distributed through the DM-Canal $\mathrm{N}^{\circ}$ 2-Canal $\mathrm{N}^{\circ} 1$.

\subsection{Experimental Design}

Before the experiment began, each subject was assigned a random ID number consisting of three digits (for example, 101 or 329) which did not affect the player's order of move or his payoffs during the experiment. The last and middle digits were determining the group's ID and subject's ID within this group in order

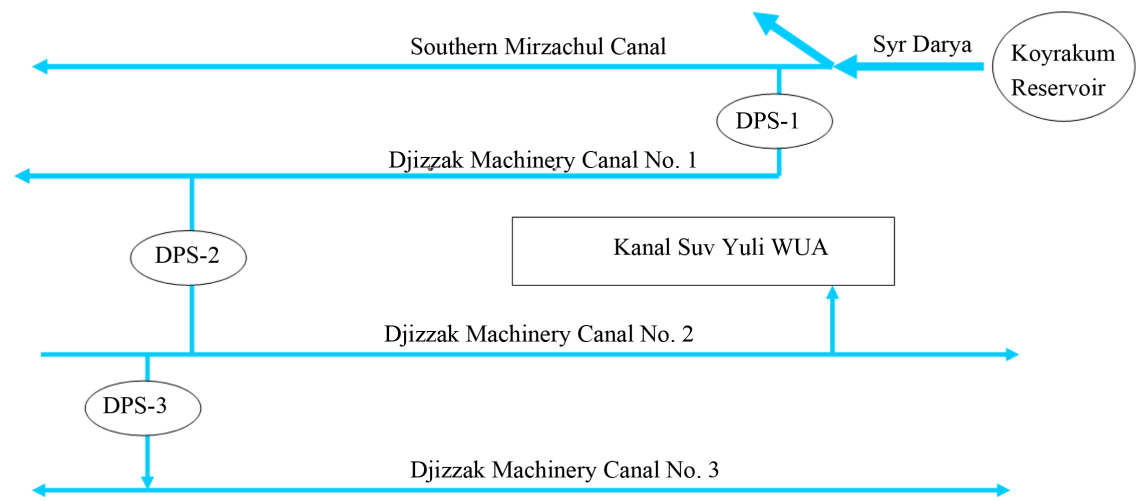

Figure 1. Irrigation system map.

${ }^{7}$ As a reference, this rainfall is similar to that in the San Diego area in California with an annual precipitation of $200 \mathrm{~mm}$.

${ }^{8}$ These crops are not only used for home consumption, but are also sold in the local markets in order to generate additional income. 
to keep track of their actions and payoffs. ${ }^{9}$

The experiment consists of the three scenarios: baseline, penalty, and bonuseach played for 15 rounds. ${ }^{10}$ Thirty farmers from the WUA in Djizzak region were randomly selected ${ }^{11}$ and divided into 3 groups (10 farmers per a group) to participate in the experiment. ${ }^{12}$ Each group were presented with a different order of scenarios: group 1-Baseline-Penalty-Bonus, group 2-Penalty-Bonus-Baseline, and group 3-Bonus-Baseline-Penalty. In total, this field experiment generated 1350 observations ( 3 groups $\times 3$ scenarios $\times 10$ farmers $\times 15$ rounds). Each subject received a pen, a set of instructions and several record sheets. Subjects had one record sheet for the trial game and three record sheets for the baseline, penalty and bonus cases. Before the experiment began, the experimenter asked subjects to read the instructions. After reading the instructions, he addressed any concerns that subjects may have. A two-period trial game of the baseline scenario was played and participants were asked to keep their scores on the trial record sheet. The objective of the trial game was to make sure that subjects understood the rules of the game.

At the beginning of every period, before subjects made a choice, the experimenter announced the total stock of the available resource, which included both permanent and additional supply of water. The permanent stock represents the amount of water in the river for irrigation, i.e. $W_{r}$, which we assume to be constant and equal to 50 units in each period. The additional stock represents the precipitation, $W_{p}$, that varies in each period and is determined through a lottery mechanism. At the start of each period the experimenter publicly announced the percentage of additional stock by randomly choosing a number between 0 and 100 percent with increments of 10 percent. The maximum amount of additional stock is 50 units. For instance, if the experimenter picked 20 percent of additional stock, then the total amount for a given period is 60 units $(50+50 \times 0.2=60)$. After the total stock is announced, subjects independently and simultaneously chose their appropriation level, $x_{i} \in[0,10]$, which was entered in their record sheet. After choosing their appropriation level, subjects were instructed to cover their numbers and put down their pens. Once all subjects had written their appropriation level on the record sheet, the experimenter asked each subject to say their number aloud. ${ }^{13}$ Although this might introduce bias as the game advances, the setting is consistent with the information set each participant faces when they make water appropriation decisions in actual practice. ${ }^{14}$

\footnotetext{
${ }^{9}$ We assigned a three-digit number, rather than a one-digit number, in order to avoid the misconception that one-digit number has a strategic position in the experiment.

${ }^{10}$ The typical time horizon in this type of experiments is between 10 and 25 periods; e.g., [19] [20] [21] and [22].

${ }^{11}$ Farmers from the Djizzak region were recruited by the chairman of WUA to participate in a group decision-making experiment for monetary reward based on their performance. All invited farmers decided to participate.

${ }^{12}$ Subjects were seated around a large table. It was not possible to arrange an individual desk for each player. Communication between them was not allowed during the experiment.

${ }^{13}$ While subjects announced their numbers, the second experimenter typed them into an Excel file to calculate players' payoffs.
} 
All subjects faced the same payoff function specified in Section 3. Due to the nature of the field experiment, and the absence of modern experiment technology, the experimenter publicly announced the total amount of resource used by the group, all subjects' actions and their corresponding payoffs in each period. Subjects were then asked to proceed to the next period, where they need to choose a new appropriation level. When the 15th round was over, the experimenter summed up subjects' payoffs for all 15 periods and publically announced the total payoffs to each subject.

Once the 15 periods of the first scenario are finished, subjects participated in two more sets of 15 periods depending on the scenario order assigned for each group. In case of the group 1, after the 15 periods of the baseline scenario, the second and third scenarios were the penalty and bonus, respectively. The experimenter distributed new instructions for the penalty and bonus games and asked subjects to read them. In the penalty (bonus) game, the player who selected the highest (lowest) appropriation level is penalized (rewarded, respectively). ${ }^{15}$ The subjects' payoffs are penalized/rewarded according to equations (5) and (7).

After each scenario, the experimenter summed up all points. In order to keep the experiment relevant to each player, the player with the highest point receive the monetary prize of 15,000 UZS (US\$6.26). After completing three scenarios, the three individuals with top total points received monetary grand prizes of 15,000 UZS (US\$6.26, first place) and 10,000 UZS (US\$ 4.17, second and third places). All subjects received a fixed amount of 20,000 UZS (US\$ 8.34) for their participation in the experiment after taking a short final survey. Average earnings per subject were 27,000 UZS (US\$ 11.26) varying between 15,000 and $60,000 \mathrm{UZS}$ (i.e. US\$ 6.26 and US\$25.03). ${ }^{16}$

\subsection{Descriptive Statistics}

Table 1 shows the descriptive statistics obtained from the survey. All participants are male farmers, 41 years old on average, and ranging from 22 to 67 years old. On average they have 17 years of experience in agriculture (ranging from 2 to 40 years), and the average family size is approximately 6 people. The average farm size is 72 hectares and farmers specialize in cotton and wheat production with a small portion of land devoted to horticultural crops and home gardens for

\footnotetext{
${ }^{14}$ In the survey, farmers acknowledge to know how much water their neighbors need, what they plant, and the size of their planted area.

${ }^{15}$ The penalized (rewarded) subject was, hence, determined endogenously by comparing his appropriation level to those of the other N-1 subjects in the group. If several subjects were tied at the maximum (minimum) level of appropriation, then all of them were penalized (rewarded) by the same amount. Subjects' penalty and reward were announced with their payoffs in each period.

${ }^{16}$ The experiment for each group lasted for about 2 hours and 50 minutes including: instructions, 2-periods trial game, the experiment and the final survey. The experiment with the first group started at 9:00 am and the last experiment with the third group finished at around 5:30 pm. The average daily temperature in this region is $0^{\circ} \mathrm{C}-10^{\circ} \mathrm{C}(32-50 \mathrm{~F})$ in November, the month in which the experiment was conducted. We provided subjects with hot tea, soft drinks and snacks.
} 
Table 1. Descriptive statistics from survey.

\begin{tabular}{|c|c|c|c|c|}
\hline Variable & Mean & $\begin{array}{l}\text { Standard } \\
\text { Deviation }\end{array}$ & Min & Max \\
\hline Age (years) & 41.20 & 11.31 & 22.00 & 67.00 \\
\hline Years in Agriculture & 16.83 & 11.03 & 2.00 & 40.00 \\
\hline Family Size (people) & 5.97 & 2.20 & 2.00 & 12.00 \\
\hline Farm Size (in hectares) & 72.40 & 39.27 & 10.00 & 179.0 \\
\hline \multicolumn{5}{|c|}{ Crop planted ( 1 if the farmer plants the crop, 0 otherwise) } \\
\hline Cotton & 0.90 & 0.31 & 0.00 & 1.00 \\
\hline Wheat & 0.97 & 0.18 & 0.00 & 1.00 \\
\hline Corn & 0.53 & 0.50 & 0.00 & 1.00 \\
\hline Onion & 0.57 & 0.50 & 0.00 & 1.00 \\
\hline Melon & 0.17 & 0.35 & 0.00 & 1.00 \\
\hline \multicolumn{5}{|c|}{ Crop Distribution on Farm (in hectares) } \\
\hline Cotton & 35.16 & 23.56 & 0.00 & 98.45 \\
\hline Wheat & 32.89 & 17.19 & 9.80 & 82.60 \\
\hline Corn & 2.94 & 3.29 & 0.00 & 10.00 \\
\hline Onion & 3.16 & 3.01 & 0.00 & 9.60 \\
\hline Melon & 0.47 & 1.18 & 0.00 & 4.00 \\
\hline \multicolumn{5}{|c|}{ Location on Irrigation Canal } \\
\hline Beginning & 0.13 & 0.35 & 0.00 & 1.00 \\
\hline Middle & 0.50 & 0.51 & 0.00 & 1.00 \\
\hline End & 0.37 & 0.49 & 0.00 & 1.00 \\
\hline
\end{tabular}

family consumption. ${ }^{17}$

The survey also reveals that farmers are somewhat knowledgeable about their neighbors, especially about the ones located close to them. ${ }^{18}$ In particular, farmers have information on the water needs of their neighbors, crops planted, and size of the planted area. In addition, only 37 percent of farmers indicate that they obtain the necessary volume of water. Farmers are not specifically charged for the amount of irrigation water they use, but instead pay a fee to the WUA based on the hectares of their property $(12,000-14,000$ UZS per hectare per year in 2014). 73 percent of them report having water conflicts with their neighbors, and 83 percent of the subjects recognize water distribution conflicts with the WUA.

\footnotetext{
${ }^{17}$ Farmers plant on average 35 ha of cotton and 33 ha of wheat, with these crops ranging from 0 to 98 ha and 10 to 83 ha, respectively. In addition, 50 - 70 percent of farmers also produce corn, onion, and melon. However, the planted area is much smaller for these crops compared to cotton and wheat. For instance, corn is grown on average on only 2.93 ha, onion on 3.16 ha and melon on 0.47 ha.

${ }^{18}$ These and other results from the survey, not reported on Table 1, can be provided by the authors upon request.
} 
Farmers also mention the existence of a penalty mechanism in the bylaw of the WUA. They believe the WUA punishes farmers for overusing water in the form of allowing them less time to irrigate (a reduction of water supply) during next period. Nonetheless, the WUA imposes no monetary fees for water overuse, nor it provides bonuses to induce conservation. The majority of the farmers (67\%) indicated that they would get involved in illegal activities to obtain the necessary volume of water for their crops (by irrigating more time than they are allowed, breaking water gates, turn off neighbor's water, etc.). From this answer we can infer that farmers are desperate for water and have to deal with water shortages on a regular basis.

\section{Results}

\subsection{Group Appropriation}

In this section, we analyze farmers' behavior under three policy scenarios: baseline, penalty, and bonus. We investigate whether subjects' choices approach to the Nash equilibrium appropriation level described in our theoretical predictions or, instead, approximate to the Socially optimal appropriation discussed in Section 3.

Table 2 presents the summary statistics of the experimental results, including the available resource stock, group appropriation and overall aggregated measurements. The second through fourth columns show the results for baseline, penalty and bonus scenario; the last column presents the overall experiment

Table 2. Experimental results.

\begin{tabular}{|c|c|c|c|c|}
\hline Indicators & Baseline & Penalty & Bonus & Overall \\
\hline \multicolumn{5}{|c|}{ Resource Stock (water units/period) } \\
\hline Average & 74.8 & 74.8 & 73.3 & 74.3 \\
\hline Standard Deviation & 16.7 & 17.2 & 17.2 & 16.9 \\
\hline Min & 50 & 50 & 50 & 50 \\
\hline Max & 100 & 100 & 100 & 100 \\
\hline \multicolumn{5}{|c|}{ Group Appropriation (water units/period) } \\
\hline Average & 68.9 & 59.6 & 44.9 & 57.8 \\
\hline Standard Deviation & 16.7 & 16.5 & 15.8 & 19.0 \\
\hline Min & 27 & 29 & 14 & 14 \\
\hline Max & 95 & 91 & 85 & 95 \\
\hline \multicolumn{5}{|c|}{ Overall Periods (water units) } \\
\hline Total Resource Stock & 3365 & 3370 & 3300 & 10,035 \\
\hline Total Appropriation & 3099 & 2681 & 2020 & 7800 \\
\hline Appropriation Rate (percentage) & 92.1 & 79.6 & 61.2 & 77.7 \\
\hline
\end{tabular}


results. The last three rows are, respectively, the total amount of resource stock, total appropriation, and appropriation rate (i.e. a percentage of the total stock). In the baseline scenario, the available stock is, on average, 75 units per round and varies between 50 and 100 units. The average level of appropriation per group is 68.9 units per period, ranging between 27 and 95 units. For this scenario, subjects choose to appropriate 92.1 percent (3099 of 3365 units) of the available stock.

In the penalty scenario (third column), the average available stock is 74.8 units per period, which is similar the baseline scenario. ${ }^{20}$ The average level of group appropriation is, however, 59.6 units per period, which is approximately a 13 percent lower than the baseline. Furthermore, the analysis of variance (ANOVA) and the Mann-Whitney test indicate that there is a statistically significant difference in average levels of appropriation by group between these two scenarios $[\mathrm{F}(1,88)=7.03 ; p<0.009]$ and $[\mathrm{z}=2.67 ; p<0.008]$, even after eliminating the observations of the first three periods in both scenarios $[\mathrm{F}(1,70)=4.28 ; \mathrm{p}<$ $0.042] .{ }^{21}$ The resource use at the group level for the penalty scenario decreases from 3099 to 2681 units in comparison the baseline scenario, a reduction of $80 \%$. Even though the level of the resource availability is slightly higher in this scenario, subjects consume less as a group than in the baseline case.

In the bonus scenario, the available resource stock is on average 73.3 units per period. $^{22}$ The average group appropriation level of water is 44.9 units per period, which is approximately a 35 (25) percent lower when compared to the baseline case (penalty case, respectively). ${ }^{23}$ In particular, over the course of the bonus scenario subjects consume only 61 percent of the available stock (2020 of 3300 units), that is considerably lower in comparison to the baseline and penalty scenarios.

Figure 2 illustrates the resource availability and group appropriation levels by scenarios and groups. Specifically, it shows that in the baseline scenarios all three groups overuse the resource stock ranging between 3 and 5 times. Furthermore, the group appropriation and resource stock levels are quite similar, often following the same pattern, especially for group 1 and 3 . This behavior may be indicative that the subject's objective is to maximize his individual payoff by

\footnotetext{
${ }^{20} \mathrm{We}$ use analysis of variance (ANOVA) and the Mann-Whitney to test for differences in appropriation across scenarios. The null hypothesis for both ANOVA and Mann-Whitney is that there is no difference between the groups.

${ }^{21}$ We eliminate the observations of the first three periods in order to avoid the effect of subjects' learning behavior at the beginning of the experiment.

${ }^{22}$ This is slightly lower than in the baseline and penalty cases, but ANOVA results show that the difference in available stock between the penalty and bonus scenarios is not significant $[\mathrm{F}(1,88)=0.18$ $\mathrm{p}=0.669]$. The difference between the baseline and bonus scenarios is small and not statistically significant either $[\mathrm{F}(1,88)=0.16 ; \mathrm{p}=0.687]$. We find similar results in comparing the baseline and penalty scenarios $[\mathrm{F}(1,88)=0 ; p=0.97]$.

${ }^{23}$ Furthermore, ANOVA results indicate a significant difference in average levels of appropriation between baseline and penalty scenarios $[\mathrm{F}(1,88)=48.98$; $\mathrm{p}<0.0001]$. Even after eliminating the observations of the first three periods, the test still indicates that there is still a significant difference $[\mathrm{F}(1,70)=38.09 ; \mathrm{p}<0.0001]$. We also find statistical differences in group appropriation between the bonus and penalty scenarios $[\mathrm{F}(1,88)=18.59 ; \mathrm{p}<0.0000]$.
} 

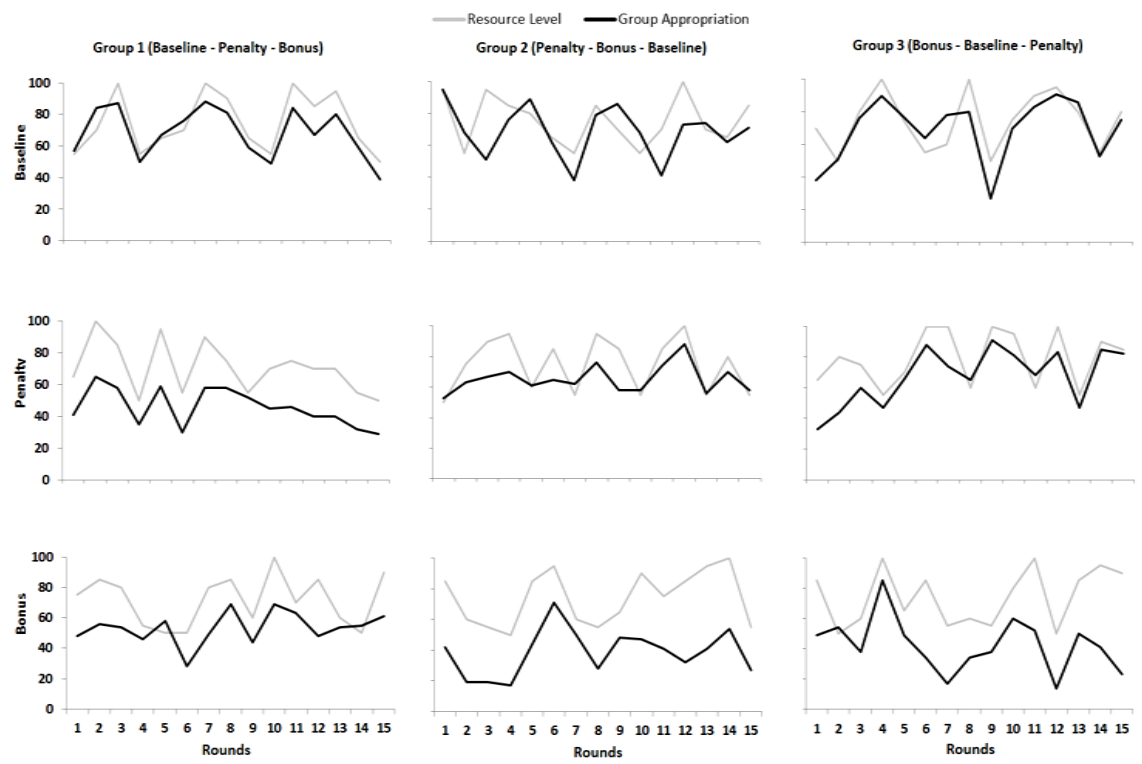

Figure 2. Resource availability and group appropriation (in water units).

consuming as much available resources as possible.

The graphs for the penalty scenario indicate that there exists a relationship between resource stock and group appropriation levels for all groups. In particular, when the resource stock decreases the appropriation level tends to increase, especially for groups 2 and 3, i.e., the gap between resource stock and appropriation levels shrinks. In addition, we observe that, the appropriation level is considerably below the resource stock level and no rounds with overuse are observed for group 1. However, subjects in group 2 and 3 overuse the available resource (5 times for group 2 and 2 times for group 3) when the resource stock exhibits a high or middle level of scarcity (when the precipitation level is less or equal to $60 \%)$. In spite of the fact that the penalty mechanism induces quite similar behavior as in the baseline scenario, it leads to a greater gap between the resource stock and group appropriation levels in comparison to the baseline case. This suggests that the penalty mechanism might not prevent the overuse of the resources when the resource stock is reduced by $30 \%$ or more.

The bonus mechanism induces two different types of individual behavior: first, subjects are influenced by the bonus to preserve the resource or, second, subjects' behavior is unaffected by the bonus, thus, exhibiting a non-cooperative behavior. The overall results from the bonus scenarios demonstrate a lower level of appropriation and a greater gap between resource stock and group appropriation levels for the three groups in comparison to the baseline scenario. However, the overuse emerges during two rounds in group 1 and during one round in group 3. This behavior occurs when the resource stock is at the lowest level (when there is no precipitation). Therefore, this result suggests that the bonus mechanism might not prevent the overuse behavior when the resource stock is at the minimum level. Despite the three cases of overuse in the bonus setting, 
this behavior is reduced compared to both the penalty and baseline scenario. ${ }^{24}$ Therefore, the fact that the number of instances in which overuse occurs is the lowest under bonus suggests that this scenario would be the most appropriate in times of scarcity.

These results are similar to the findings of the experiment with the penalty and bonus treatments conducted by [18] that show that both treatments significantly reduce the use of the resource use. However, our findings also indicate that an overuse of the resource might occur under the penalty and bonus scenarios when the stock reaches some certain level of scarcity.

\subsection{Comparison with Theoretical Predictions}

We next compare the observed appropriation levels with the theoretical predictions discussed in Section 3. Figure 3 illustrates the average individual appropriation levels versus the theoretical predictions, i.e., Nash and Socially optimal equilibrium, as well as the per period resource level.

The graphs suggest a significant difference between the average appropriation level, the NE and the SO depending on the scenario type and subjects' group. The appropriation levels in the baseline scenario illustrate similar variation across three groups. The subjects' average appropriation level is centered around the NE, except several rounds when the water stock is low and the appropriation level reach the SO. These results indicate that the SO appropriation level can be occasionally achieved without imposing any incentive mechanism when the resource stock is at the lowest level. However, the group appropriation is less likely to preserve any of the available stock. Table 3 presents the average appropriation
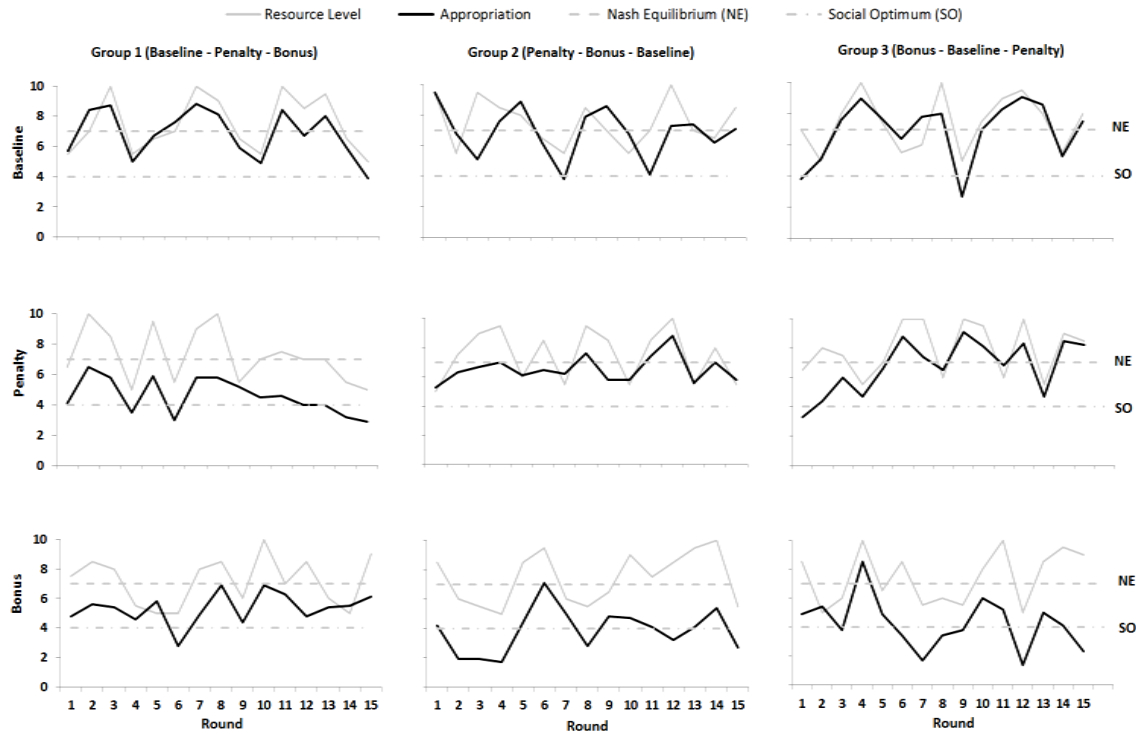

Figure 3. Average appropriation vs. theoretical prediction (in water units).

${ }^{24}$ To put in perspective, across all groups, we find 14 instances of overuse under the baseline scenario and 11 total instances of overuse under both penalty and bonus. For each scenario, we played 15 rounds per group. 
Table 3. Average individual appropriation by groups and scenarios.

\begin{tabular}{ccccc}
\hline & \multicolumn{3}{c}{ Individual Appropriation Level } \\
\hline & Baseline & Penalty & Bonus & All Scenarios \\
\hline Group 1 & 6.85 & 4.59 & 5.35 & 5.59 \\
Group 2 & 6.89 & 6.53 & 3.87 & 5.76 \\
Group 3 & 6.93 & 6.76 & 4.25 & 5.98 \\
All Groups & 6.89 & 5.96 & 4.49 & 5.78 \\
\hline
\end{tabular}

level per subject indicating that the appropriation level is quite similar across three groups. Even though subjects on average consume 6.89 units of water that is slightly below the NE, ANOVA results indicates that there is no a significant difference between the average appropriation level and the NE theoretical prediction $[\mathrm{F}(1,449)=0.52 ; \mathrm{p}=0.471]$. Only 9.6 percent of all subjects' decisions coincide with the NE. This is similar to the experiment results in [7] in which the pattern of individuals' decision does not converge to the NE. On average, subjects also appropriate above the social optimal level across the three groups. In addition, ANOVA and the Mann-Whitney test show that the average appropriation level is statistically different from the social optimum at any statistical level $[\mathrm{F}(1,449)=337.46 ; \mathrm{p}<0.000]$ and $[\mathrm{z}=14.00 ; \mathrm{p}<0.000]$.

In the case of the penalty scenario, Figure 3 shows that there is less variation in subjects' choices and the gap between the appropriation level and resource stock is greater than the baseline scenario. Similar to the baseline scenario, the appropriation level in the penalty scenario strongly depends on the available stock. The graphs for group 2 and 3 contain several instances of resource overuse when the resource stock reaches a minimum level. Unlike the baseline case, the penalty induces subjects to overuse the resource when the available stock is scarce. This behavior could be rationalized by the fact that a penalty makes subject feel less guilty about their overconsumption and implicitly provides an incentive to over-use the resource.

The average appropriation level for penalty scenario is 5.96 units of water for all three groups. The greater shift in the appropriation level is particularly observed in the group 1 where subject on average consumed 4.6 units of water per a round, approaching toward the SO. The average appropriation levels for group 2 and 3 are 6.53 and 6.76 that is slightly lower in comparison to the appropriation levels in the baseline scenario. Overall, however, only 11 percent of all individual decision are consistent with the NE predictions. ${ }^{25}$ This coincides with the experiment results in [13] which indicate that sanctions, such as a penalty, can increase efficiency. The average level of appropriation among all groups is above the social optimum, except last four rounds of group 1 and the first round of group 3 . While the penalty mechanism compels subjects to choose the social op-

${ }^{25}$ Specifically, the analysis of variances indicates that there is a significant difference between the average appropriation level and the $\mathrm{NE}[\mathrm{F}(1,449)=63.46 ; \mathrm{p}<0.000]$. Furthermore, the Mann-Whitney test rejects the null hypothesis of equal population medians at any statistical level $[\mathrm{z}=-6.68$; $\mathrm{p}<$ $0.000]$. 
timal level in these 5 periods, only 9 percent of all choices coincide with the socially optimal level. Indeed, an analysis of variance and the Mann-Whitney test indicate that the average appropriation level is statistically different from the social optimum at any statistically significant level $[\mathrm{F}(1,449)=223.94 ; \mathrm{p}<0.000]$ and $[\mathrm{z}=12.15 ; \mathrm{p}<0.000]$.

Finally, as is shown in Figure 3, under the bonus scenario the average appropriation level is consistently below the NE during all rounds across three groups, except the 4 th round of group 3 when the resource stock reached the maximum level. Nonetheless, regardless the precipitation level, subjects appropriate on average substantially less under the bonus scenario than in baseline case (4.48 vs 6.89 units), suggesting that the bonus mechanism is most effective in conserving the resource. In addition, the average level of individual appropriation under the bonus mechanism is $25 \%$ lower in comparison to the penalty. Figure 3 also indicates that, unlike the penalty mechanism, which induces subjects to voluntarily appropriate an amount close to the NE, the bonus mechanism does not lead to the NE level of appropriation, on average. Indeed, only 4 percent of all decisions in the bonus scenario coincide with the NE predictions. ${ }^{26} \mathrm{We}$ also observe that the average appropriation is centered on the socially optimal (SO) in comparison to the baseline and penalty scenarios. It is at or lower than the social optimum in one third of all rounds (about 54\% of all decisions). Furthermore, ANOVA and Mann-Whitney results show that the average appropriation level is statistically different from the social optimum $[\mathrm{F}(1,449)=6.34 ; \mathrm{p}=0.012$ and $\mathrm{z}=-3.55 ; \mathrm{p}<$ $0.00]$.

\subsection{Scarcity versus Non-Scarcity Comparison}

We next study how the availability of the resource stock impacts the cooperation among farmers. In particular, we analyze the appropriation behavior when the resource stock is scarce versus non-scarce. We assume that the resource stock is scarce when available resource stock is less or equal 75 units (that is equivalent to less or equal of $50 \%$ of precipitation according to the experiment setting) and non-scarce when it is more than 75 unites (i.e., more than $50 \%$ of precipitation).

Based on this assumption, $56 \%$ of all rounds in the baseline and penalty scenarios are labeled as scare and $51 \%$ in the bonus scenario.

Table 4 shows the comparison of individual appropriation based on nonscarce versus scarce for the three different scenarios. The appropriation level is considerably less when resource stock is scarce in comparison to when it is nonscarce. ANOVA and the Mann-Whitney tests indicate that there is a statistically significant difference between the two groups of water availability for all scenarios. $^{27}$ From an institutional perspective, the bonus scenario exhibits the highest

\footnotetext{
${ }^{26}$ ANOVA and the Mann-Whitney tests confirm this finding, since there is a significant difference between the average appropriation level and the $\mathrm{NE}[\mathrm{F}(1,449)=167.15 ; \mathrm{p}<0.000]$ and $[\mathrm{z}=-11.16$; $\mathrm{p}$ $<0.000]$.

${ }^{27}$ ANOVA results are $\mathrm{F}(1,1349)=84.50 ; \mathrm{p}<0.00$. Mann-Whitney results are $\mathrm{z}=9.24 ; \mathrm{p}<0.00$. Results suggest that we may reject the null hypothesis that appropriation is similar across scarce and non-scarce scenarios, controlling for policy scenarios.
} 
Table 4. Average individual appropriation comparison by resource availability

\begin{tabular}{ccccc}
\hline & \multicolumn{3}{c}{ Individual Appropriation Level } \\
\hline & Overall & Non-Scarce & Scarce & Difference \\
\hline Baseline & 6.89 & 8.01 & 5.99 & $2.02^{\star}$ \\
Penalty & 5.96 & 7.11 & 4.95 & $2.17^{\star}$ \\
Bonus & 4.49 & 5.14 & 3.87 & $1.28^{\star}$ \\
All Scenarios & 5.78 & 6.71 & 4.96 & $1.75^{\star}$ \\
\hline
\end{tabular}

Note: ${ }^{\star} 1$ percent significance level based on the Mann-Whitney and ANOVA tests.

reduction in water appropriation relative to the baseline scenario $(43.65 \%$ under non-scarcity and $43.25 \%$ under scarcity). Relatively speaking, the penalty scenario exhibits an overall lower percentage change compare to the baseline scenario, under both non-scarcity and scarcity (11.90\% and $19.01 \%$, respectively). However, as statistical testing suggests, there is a reduction in appropriation under both policies, regardless of scarcity level. Although there is a greater reduction in appropriation under the penalty scenario, when moving from non-scarcity to scarcity, the bonus scenario shows a lower overall appropriation regardless of the level of stock. ${ }^{28}$ This suggests that, if policymakers are able and interested in increasing the stock of water over time at a higher rate, then a policy similar to the bonus scenario would be able to achieve such a goal. However, this recommendation does not take into account the concomitant effect on crops due to less water employed and/or the need to switch to less water-intensive crops.

\subsection{Location Comparison}

As a final aspect of this investigation, we analyze the level of appropriation given the subject's stated location along the irrigation system. Table 5 shows the average appropriation levels for subjects who stated to be located at the beginning, middle and end of the irrigation system for each of the three scenarios.

In the baseline scenario, subjects located in the middle of the irrigation system appropriate more than those in the other two locations (i.e., 7.09 units). Under the penalty and bonus scenario, subjects at the end of the irrigation system are the ones appropriating the most (6.32 units and 5.30 units, respectively), whereas subjects located at the beginning appropriate the least $\left(5.10\right.$ units). ${ }^{29}$ Similar to our findings in the previous subsection, water appropriation is reduced more under the bonus scenario than the penalty scenarios, compared to the baseline. We also find that, overall, regardless of scenario, individuals at the end of the irrigation system appropriate more water. That is, a disadvantageous location emphasizes the overuse of the resource.

These findings make evident that subjects' location within the irrigation

${ }^{28}$ Water appropriation is reduced by $30.52 \%$ under penalty, $25.21 \%$ under baseline, and $24.90 \%$ under bonus when switching from non-scarce to scarce.

${ }^{29}$ Appropriation choices under penalty and bonus were not statistically different from each other. 
Table 5. Average individual appropriation by location.

\begin{tabular}{cccc}
\hline & \multicolumn{3}{c}{ Individual Appropriation Level } \\
\hline & Baseline & Penalty & Bonus \\
\hline Beginning & 6.30 & 5.10 & 3.08 \\
Middle & 7.09 & 5.92 & 4.27 \\
End & 6.82 & 6.32 & 5.30 \\
Overall & 6.89 & 5.96 & 4.49 \\
\hline
\end{tabular}

system has an impact on their decision. ${ }^{30}$ In particular, individuals whose farms are located at the beginning of the irrigation system are more sensitive to the introduction of penalty (or bonus) mechanisms that promote conservation than other farmers located at the end of the system. For instance, the introduction of penalties reduces the appropriation levels of farmers at the beginning of the irrigation system by 19 percent, but only reduces the appropriation level of farmers located at the end of the irrigation system only by 7 percent. Implementation of the bonus scenario has similar effect but with much greater magnitude.

We also note that, if policymakers wish to pursue a policy change in water appropriation that is more equitable, in terms of percent reduction, then an institutional arrangement consistent with the penalty scenario would be more appropriate. If the objective is to greatly reduce water appropriations, then bonus would be the suggested alternative.

\section{Conclusions}

Irrigation water is a constrained common pool resource in Uzbekistan that leads to an increasing competition over water allocation among farmers. Irrigation networks and policies, both created during the Soviet era, are putting more pressure on water reserves in this region. If such inefficient use of water resources continues, which focuses on agricultural output and ignores environmental impacts, the Uzbek's agricultural sector will be negatively affected. In this study we compared the effectiveness of penalty and bonus policies for efficient use of irrigation water among farmers in Uzbekistan. In particular, we investigated their water appropriation behavior, and evaluated the benefits of these two policies in terms of how they help to ameliorate the overuse of the resource.

Our experimental results demonstrate that, when protective policies are absent (baseline), farmers consistently overuse the resource without internalizing the negative externality that their overconsumption imposes on other farmers. Experience during the Soviet era, when the use of water was very inefficient, leads farmers to this myopic behavior, which emerges in the form of higher le-

\footnotetext{
${ }^{30}$ Location parameters are not considered into the payoff function. However, we observe different appropriation due to the subjects' location on the irrigation channel in the real life. The subject distribution by the groups and location is following: i) group\#1: at the beginning 1 subject, middle 6 subjects and end 3 subjects, ii) group \#2: at the beginning zero subject, 6 in the middle and 4 subjects at the end, iii) group \#3: 3 subjects at the beginning, 3 in the middle and 4 subjects at the end.
} 
vels of appropriation. Similar to [7], our experimental results provide evidence that subjects appropriate more than Nash and the social optimal. In addition, our findings suggest that both penalty and bonus mechanisms reduce water appropriation relative to the baseline case. This coincides with the experimental results from [12]. However, our findings suggest that the bonus mechanism is the more effective in preserving the resource stock in comparison to their conclusion of the penalty mechanism being more effective.

We evaluated farmer's choice when the resource stock is scarce and non-scarce and how it impacts cooperation among them. Our results indicate that the appropriation level is lower when the resource stock is scarce for the baseline scenario, however, we identify overuse of the resource in the penalty scenario. This behavior can be rationalized by the fact that a penalty gives an implicit right to the farmer to overuse the resource when the stock is scarce.

We also analyzed farmer's behavior based on their actual location within the irrigation system. The experimental results suggest that farmers who are located at the beginning of the irrigation system appropriate less in comparison to the ones at the end, who choose to appropriate most of the resource. This can be explain by the fact that, in real life, Uzbek farmers location at the end of the canal face a lot of uncertainty related to the timely water supply and they use any available resources to irrigate since the next opportunity is unknown to them. Our experimental results further confirm that there is a reduction in the appropriation level under the penalty and bonus scenarios regardless of farmer's location. However, farmers from different locations behave differently to the introduction of these policies and, furthermore, it impacts the magnitude of the decrease in the appropriation level.

This paper contributes to the current discussion among water specialists in Uzbekistan about the benefits of introducing a bonus mechanism to reward farmers for their efficient use of water resources. The above results indicate that a government agencies concerned about efficient water use might consider the implementation of penalties and/or bonuses. These policies are effective at reducing individual appropriation levels relative to the benchmark case, especially when the bonus mechanism is in place.

Another important policy conclusion from this analysis is that policymakers have options to address shortfalls in water supply throughout the growing season. If the area is experiencing a severe drought, then an institutional arrangement similar to the bonus scenario would provide incentives to reduce water use. This has certain appeal for farmers, as they would receive a form of compensation from lost crops. Finally, the findings of this study can be potentially extended to other Central Asian countries that have similar climate conditions and face a similar situation with respect to the water resource management for irrigation at the WUA level.

\section{Acknowledgements}

We would like to thank Jill McCluskey, Felix Munoz-Garcia, Ron Mittelhammer, 
Robert Rosenman, Walt Butcher, Phil Wandschneider, Douglas Young, Hayley Chouinard and Andrew Cassey for their useful comments and suggestions. We also thank the Water Users Associations in Uzbekistan for hosting the experiment and Ravshan Boyirov for assisting to conduct this experiment. Finally, we gratefully acknowledge the financial support from the Jeff Krautkraemer "Pay it Forward" Scholarship.

\section{References}

[1] Guadagni, M., Raiser, M., Crole-Rees, A. and Khidirov, D. (2005) Cotton Taxation in Uzbekistan. The World Bank, ECSSD Working Paper No 41. http://r0.unctad.org/infocomm/anglais/cotton/Doc/Uzbek_TAX.pdf

[2] Ostrom, E. (2006) The Value-Added of Laboratory Experiments for the Study of Institutions and Common-Pool Resources. Journal of Economic Behavior and Organization, 61, 149-163. https://doi.org/10.1016/j.jebo.2005.02.008

[3] Ostrom, E. (2011) Reflections on Some Unsettled Problems of Irrigation. American Economic Review, 101, 49-63. https://doi.org/10.1257/aer.101.1.49

[4] Dinar, A. and Wolf, A. (1997) Economic and Political Considerations in Regional Cooperation: Economic and Political Perspective in the Western Middle East. Agricultural and Resource Economics Review, 26, 7-22.

https://doi.org/10.1017/S1068280500000794

[5] Dinar, A. (2004) Cooperation in Managing Transboundary Water Resources: Evaluation Approaches and Experiences. Paper Presented at the 4th Rosenberg International Forum on Water Policy, Ankara.

[6] Abbink, K., Moller, L.C. and O’Hara, S. (2005) The Syr Darya River Conflict: An Experimental Case Study. Center for Decision Research and Experimental Economics, University of Nottingham, CeDEx Discussion Paper No. 2005-14.

[7] Walker, J.M., Gardner, R. and Ostrom, E. (1990) Rent Dissipation in a Limited-Access Common-Pool Resource: Experimental Evidence. Journal of Environment Economics and Management, 19, 203-211. https://doi.org/10.1016/0095-0696(90)90069-B

[8] Rutte, C., Wilke, H.A.M. and Messick, D.M. (1987) Scarcity and Abundance Caused by People or the Environment as Determinants of Behavior in the Resource Dilemma. Journal of Experimental Social Psychology, 23, 208-216. https://doi.org/10.1016/0022-1031(87)90032-1

[9] Budescu, D.V., Rapoport, A. and Suleiman, R. (1992) Simultaneous vs. Sequential Requests in Resource Dilemmas with Incomplete Information. Acta Psychologica, 80, 297-310. https://doi.org/10.1016/0001-6918(92)90052-F

[10] Rapoport, A., Budescu, D.V. and Suleiman, R. (1994) Sequential Requests from Randomly Distributed Shared Resources. Journal of Mathematical Psychology, 37, 241-265. https://doi.org/10.1006/jmps.1993.1015

[11] Apesteguia, J. (2006) Does Information Matter in the Commons? Experimental Evidence. Journal of Economic \& Behavioral Organization, 60, 55-69. https://doi.org/10.1016/j.jebo.2004.08.002

[12] Rapoport, A. and Tung Au, W. (2001) Bonus and Penalty in Common Pool Resource Dilemmas under Uncertainty. Organizational Behavior and Human Decision Processes, 85, 135-165. https://doi.org/10.1006/obhd.2000.2935

[13] Casari, M. and Plott, C.R. (2003) Decentralized Management of Common Property 
Resources: Experiments with a Centuries-Old Institution. Journal of Economic Behavior and Organization, 51, 217-247. https://doi.org/10.1016/S0167-2681(02)00098-7

[14] Hackett, S., Schalager, E. and Walker, J. (1994) The Role of Communication in Resolving Commons Dilemmas: Experimental Evidence with Heterogeneous Appropriators. Journal of Environmental Economics and Management, 27, 99-126. https://doi.org/10.1006/jeem.1994.1029

[15] Gardner, R., Herr, A., Ostrom, E. and Walker, J.A. (2000) The Power and Limitations of Proportional Cutbacks in Common-Pool Resources. Journal of Development Economics, 62, 515-533. https://doi.org/10.1016/S0304-3878(00)00095-X

[16] McCusker, C. and Carnevale, P.J. (1995) Framing in Resource Dilemmas: Loss Aversion and the Moderating Effects of Sanctions. Organizational Behavior and Human Decision Processes, 61, 190-201. https://doi.org/10.1006/obhd.1995.1015

[17] Komorita, S.S. and Barth, J.M. (1985) Components of Reward in Social Dilemmas. Journal of Personality and Social Psychology, 48, 364-373. https://doi.org/10.1037/0022-3514.48.2.364

[18] Yamagashi, T. (1986) The Provision of a Sanctioning System as a Public Good. Journal of Personality and Social Psychology, 51, 110-116. https://doi.org/10.1037/0022-3514.51.1.110

[19] Ostrom, E., Gardner, R. and Walker, J. (1994) Rules, Games and Common-Pool Resources. University of Michigan Press, Ann Arbor. https://doi.org/10.3998/mpub.9739

[20] Herr, A., Gardner, R. and Walker, J.M. (1997) An Experimental Study of Time-Independent and Time-Dependent Externalities in the Commons. Games and Economic Behavior, 19, 77-96. https://doi.org/10.1006/game.1997.0541

[21] Keser, C. and Gardner, R. (1999) Strategic Behavior of Experienced Subjects in a Common Pool Resource Game. International Journal of Game Theory, 28, 241-252. https://doi.org/10.1007/s001820050108

[22] Walker, J.M., Gardner, R., Herr, A. and Ostrom, E. (2000) Collective Choice in the Commons: Experimental Results on Proposed Allocation Rules and Votes. The Economic Journal, 110, 212-234. https://doi.org/10.1111/1468-0297.00497 